\title{
Sobre a história da saúde pública: idéias e autores
}

\author{
On the history of public health: ideas and authors
}

\footnotetext{
${ }^{1}$ Departamento de Medicina Preventiva e Social, Faculdade de Ciências Médicas da Universidade de Campinas, Cidade Universitária Zeferino Vaz 13081-970, Campinas, SP rnunes@correionet.com.br
}

\begin{abstract}
The aim of this report is to outline a first approach on the studies dealing with public history in Brazil. This presentation does not intend to embrace all the literature on this subject, either regarding diseases or institutions. Reports were limited to those emphasizing historical periods and presenting a general view of the public health development. After considering the installation of Brazilian social medicine project - from colonial periods to the first decades of nineteenth century - we analyzed studies comprising the public health history from 1870-1930. The period from 18891930, also known as Old Republic, with very specific characteristics in Brazilian socioeconomic and public history, has been stressed.

Key words Social Medicine; Public Health, History; Historical Studies; Brazil; XIX-XX Centuries
\end{abstract}

Resumo O trabalho tem como objetivo traçar uma primeira aproximação com os estudos que tratam da história da saúde pública no Brasil. Não pretende abarcar toda a literatura que trata da saúde pública em sua vertente histórica, mas enfatizar os trabalhos, que ao destacar períodos históricos, oferecem um panorama geral da saúde pública, sem detalhar estudos sobre doenças ou instituições. Após tratar de como se instaura o projeto da medicina social brasileira, desde o período colonial até as primeiras décadas do século XIX, trabalha-se com os estudos que abarcam a história da saúde pública entre 1870 e 1930. Destaca o período de 1889-1930, também conhecido como República Velha, que tem características específicas na história socioeconômica e política brasileira.

Palavras-chave Medicina Social; Saúde Pública; História; Estudos Históricos; Brasil; Séculos XIX-XX 


\section{Introdução}

O objetivo deste trabalho é traçar uma primeira aproximação sobre os estudos que têm procurado reconstituir a história da saúde pública no Brasil. Mesmo considerando a importância das tendências históricas do perfil epidemiológico, que muitas vezes fazem parte das análises sobre as práticas sanitárias, ou mesmo constituem objeto per se de análises históricas, esta apresentação estabelece um recorte bastante definido, referindo-se somente a alguns poucos "estudos de casos", que tomam como referência os trabalhos que analisam de maneira global o desenvolvimento das práticas sanitárias, em determinados períodos históricos, em uma perspectiva que se pode denominar de história social. Nesse sentido, é oportuna a consideração feita por Meihy e Bertolli Filho (1990) quando assinalam que "não se situando como uma espécie historiográfica, nem se alargando nos cômodos preparos que apelam indefinidamente para a "pluri", "multi" ou "trans" disciplinaridade, a história da saúde pública se coloca como uma variação ou ramo da história social, espaço útil para se refletir sobre a continuidade e/ou ruptura das relações entre o poder, as atitudes médicas vinculadas à população em geral e as implicações íntimas, constantes na prática da ética política. Trata-se de uma história da circulação da vontade governante manifestada nos cuidados médicos e nas aceitações populares".

$\mathrm{Na}$ medida que foram definidos os limites deste trabalho, procurou-se situar na bibliografia brasileira as pesquisas que se enquadrassem na temática apontada. A primeira verificação é que, excetuando-se trabalhos esparsos, escritos em datas anteriores, a preocupação com o assunto despontou nos anos $70 \mathrm{e}$ tem maior florescimento na década de 1980 . Já em 1971, Blount abre a sua tese sobre o movimento sanitário em São Paulo com o seguinte: "Pesquisadores no comparativamente novo campo da história da saúde pública têm tentado concentrar seus estudos em nações que primeiro implementaram programas governamentais de sanitarismo e mais tarde contribuíram para as descobertas bacteriológicas das últimas décadas do século XIX.

Consequentemente, regiões subdesenvolvidas da África, Ásia e América Latina têm sido negligenciadas em favor das nações industrializadas na Europa e América do Norte. Na medida que os cientistas sociais tornam-se crescentemente conscientes da relação entre a saúde e o processo de desenvolvimento, parece, agora, apropriado examinar a saúde pública e higiene em sociedades pré-industriais. Através de tais estudos os historiadores médicos podem determinar o impacto dos avanços da saúde européia e americana sobre outros países. Além disso, especialistas regionais entenderão melhor os fatores sociais, econômicos e políticos que influenciaram a ação ou a passividade governamental em saúde pública dentro de suas áreas de interesse" (Blount, 1971).

Também Luz (1982) argumenta, ao apresentar o plano de pesquisa dos discursos médicos sobre a saúde que se estendem dos anos 70 do século XIX aos anos 20 do século XX, no sentido de apreender como ocorreu a constituição das instituições de saúde, a existência de uma "limitada bibliografia em que se possa basear para situar a questão da história institucional da saúde". Acrescentava que, "grosso modo, poderíamos dizer que o fato histórico, no Brasil, ainda é em grande parte tratado como sucessão de nomes, datas e fatos importantes, relações mecânicas de causas e conseqüência, que fazem ressurgir e reafirmar a providência divina ou o Estado como agentes estabelecedores da ordem, nos momentos em que os indivíduos ou grupos tentam desvirtuar o povo "ordeiro, pacífico e trabalhador" dos rumos a ele destinados". Em resumo: “O saber histórico se confunde com o mito histórico, cansado "mito" que ainda resiste e confunde o pensar histórico”.

Outro estudioso das origens e desenvolvimento das práticas sanitárias no Estado de São Paulo, Mehry (1985), lembra que "a maioria dos estudos sobre saúde pública realizados no Brasil apresentam, como característica principal, o fato de considerarem o objetivo das práticas sanitárias como anistórico, ao mesmo tempo que conferem uma dada historicidade a este campo de práticas, a partir da história dos meios de realização deste objetivo. O que diferencia as etapas históricas, nesses estudos, é a evolução científica destes meios ao longo do tempo, ou seja, o que caracteriza os sucessivos períodos é a incorporação de um maior ou menor grau de cientificidade e/ou racionalidade àqueles meios".

Interessante é a observação de Moraes (1983), quando diz "a ausência da questão da saúde na bibliografia histórica brasileira, no que diz respeito às condições de vida e de trabalho e de seus aspectos institucionais, pode 
nos conduzir a pensar numa negligência em considerar e analisar este tema. Se observarmos, entretanto, jornais, peças teatrais, músicas e textos produzidos principalmente por anarquistas, de forma bastante difusa, e por socialistas - um pouco mais sistematicamente, vamos concluir que as condições de existência das populações urbanas não eram esquecidas nas duas primeiras décadas deste século, ao menos por artistas e militantes políticos".

Sem dúvida, mesmo com todas as dificuldades inerentes aos estudos históricos em saúde, há esforços em realizar pesquisas nesse campo e já despontam algumas análises sobre as próprias tendências predominantes nesses estudos. Nesse sentido, são referências importantes: Luz (1982), Carvalho e Lima (1992).

Como assinalado no início, esta apresentação não pretende dar conta de toda literatura que vem tratando da saúde pública em sua vertente histórica, quer seja em relação à doença, ou às instituições, mas aos trabalhos que, ao destacarem períodos históricos, fornecem um panorama geral do desenvolvimento da saúde pública. Carvalho e Lima (1992) salientam que uma forma de aproximar-se dos dilemas presentes na produção do conhecimento em ciências sociais, e da história quando a referência é à saúde coletiva, é verificar qual é o significado que os trabalhos produzidos atribuem à reconstrução histórica.

\section{Reconstruindo a história}

\section{A medicina social brasileira: a instauração de um projeto}

Inegavelmente, quando se fala em reconstruir a história da medicina brasileira a fim de demarcar a emergência de um projeto de medicina social, o texto de Roberto Machado e colaboradores (1978) torna-se referência obrigatória. Entre outros motivos, porque, como será visto adiante, existe uma concentração de estudos que destacam um determinado período da história brasileira - o da Proclamação da República, entre 1889 e 1930, também conhecido como período da República Velha; e este originalíssimo estudo dedica-se a descobrir como surge a tematização da saúde como objeto da medicina, em lugar da doença e, ao mesmo tempo, como ocorreu o processo de medicalização da sociedade brasileira. Traça um extenso panorama que abrange o período colonial até as primeiras décadas do século XIX. É considerado um texto pioneiro na "caracterização da medicina como poder disciplinar cuja ação recairia sobre a vida social urbana" (Carvalho e Lima, 1992). Assim, os estudiosos evidenciam a emergência de um projeto de medicina social para o início do século XIX, vinculado, sobretudo, à higiene pública e medicalização do espaço urbano, e isto irá ocorrer no quadro de transformações que se impôs com a transferência da Corte portuguesa, em 1808.

Segundo Machado e colaboradores (1978), "a administração portuguesa não se caracterizou, pelo menos até a segunda metade do século XVIII, pela organização do espaço social, visando um ataque planificado e continuado às causas de doença, agindo, por isso, de modo muito mais negativo que positivo, no que diz respeito à saúde". O estudo detalhado de documentos, periódicos, cartas, ofícios e teses irá evidenciar que o tema da saúde, por si mesmo, não forma parte do projeto colonial, e somente pode ser registrado no momento em que, a medicina se volta sobre a cidade, disputando um lugar entre os organismos de controle da vida social. Considera, assim, que embora a saúde da população, especialmente no combate à lepra e à peste, e a existência de algum controle sanitário em relação aos portos, ruas, casas e praias, tenha sido objeto de atenção da administração portuguesa em fases anteriores, a transformação do objetivo da medicina, da doença para a saúde, irá ocorrer somente no século XIX, quando "o conhecimento da colônia é colocado como fundamento necessário para uma intervenção dirigida para o aumento da produção, para a defesa da terra, para a saúde da população" (Machado et al., 1978).

Nessa época são desenvolvidas ações reguladoras, incluindo as atividades dos cirurgiões, e a criação das primeiras escolas de medicina: na Bahia é criada a Escola de Cirurgia, em 1808; e no Rio de Janeiro, a cátedra de anatomia no Hospital Militar, seguida pela de medicina operatória, em 1809. Porém foi em 1829, com a criação da Sociedade de Medicina e Cirurgia do Rio de Janeiro, "que lutará, de diversas maneiras, para impor-se como guardiã da saúde pública” (Machado et al., 1978), que se inicia a implantação da medicina social no Brasil, que lutará também pela defesa das ciências médicas. Desde a sua fundação pode-se observar a influência que a sociedade irá exercer so- 
bre as decisões governamentais, no que se refere à saúde pública. Ela irá apresentar um amplo programa que se estende desde a higiene à medicina legal; educação física das crianças; a questão dos enterros nas igrejas; denunciará a carência de hospitais; estabelecerá regulamentos sobre as farmácias; medidas para melhorar a assistência aos doentes mentais; denunciará também as casas insalubres e repletas de pessoas; e dará destaque ao saneamento. Era necessário, como escreve Oliveira (1983), "um discurso que desse conta das condições de saúde nos centros urbanos, que já nessa época havia alcançado uma importância crescente, no comércio e na produção, além de ser a sede do poder do Estado, um importante conservador das doenças".

Destaca-se que o conhecimento do meio é básico, para o qual concorre a influência da teoria miasmática. De um modo geral, esse pensamento irá ser permeado por duas categorias de análises: o natural e o social. Assim, "diagnosticada a desordem urbana, a medicina compreendeu que era determinada por causas naturais - a situação geográfica em geral e os acidentes geográficos como pântanos e montanhas - e sobretudo, como provenientes de causas sociais - tanto no nível macrossocial, do funcionamento geral das cidades, como no nível microssocial das instituições" (Oliveira, 1983). Dessa forma, o exame minucioso do urbano será complementado com a análise dos espaços específicos que representam perigo de doença e de desordem. Medicalizar as instituições - hospitais, cemitérios, escolas, quartéis, fábricas e prostíbulos - torna-se imperativo.

Ao propor a ordem urbana, não se esquecia que se estabelecia, também, "uma nova relação: ordem-moral-saúde. Com esta nova relação, tenta-se generalizar e obter o acordo dos grupos sociais acerca da ordem e da moral, necessária para a manutenção do poder do Estado" (Oliveira, 1983).

Fica claramente demonstrado, no estudo de Machado, que o projeto de medicina social que se implanta nesse momento, "tem sob sua mira a transformação da cidade - e principalmente da Corte - promovendo seus habitantes livres a indivíduos saudáveis e patriotas, perfeitos cidadãos" (Machado et al., 1978). Oliveira (1983), ao retomar este trabalho, acentua o fato deste projeto de medicina social ter sido organizado numa formação social cujo grupo social mais importante é agrário-exportador, baseado em mão-de-obra escrava. Por- tanto, "Enquanto projeto de medicina que se ocupa do espaço urbano, sua atenção estará voltada principalmente para a força de trabalho urbano". Como afirmam Machado e colaboradores (1978) "No momento de sua constituição, a medicina social brasileira não é uma medicina do trabalho ou do proletariado, mas uma medicina urbana".

Facilmente pode-se constatar que este trabalho continua a tradição inaugurada por Michel Foucault, não somente em relação à orientação "arqueológica" por ele criada e desenvolvida (Foucault, 1978), mas na sua interpretação das origens da medicina social européia (Foucault, 1979). Em especial, quando este autor analisa o processo de medicalização e conseqüente disciplinarização da vida social no que denominou, no caso da França, de "medicina urbana”. Carvalho e Lima (1992), depois de uma aprofundada análise do binômio cidade/saúde e da força explicativa que assumiu na historiografia européia e posteriormente estendeu-se aos países do Terceiro Mundo, ou seja, a associação causal entre "doença" e "cidade massiva”, passam a levantar alguns problemas quanto ao estudo de Machado e colaboradores.

Dentre os pontos levantados salientam o do papel atribuído à medicina como configuradora do projeto de higienizar e disciplinar a cidade e seus habitantes, que é visto "como portador de um sentido que transcenderia a intervenção médico-sanitária sobre o espaço urbano, constituindo-se em elemento essencial ao desenvolvimento do capitalismo, uma vez que criaria as condições socioculturais de sua emergência" (Carvalho e Lima, 1993). Pelo pouco esclarecimento das características da população urbana e das relações sociais e pelo motivo apontado acima, as autoras são críticas em relação à transposição do modelo explicativo europeu e também pelo fato de "privilegiarem como documento o discurso institucional, sem atenção para o contexto onde esse discurso é elaborado". Mesmo com essas críticas, reconhecem que a investigação traz importante contribuição ao conhecimento do projeto idealizado pelos intelectuais médicos na segunda metade do século XIX, tendo faltado esclarecer quais foram as condições que possibilitaram a sua emergência. De outro lado, não se pode deixar de reconhecer o que há de altamente positivo neste estudo, e alguns desses pontos podem ser sintetizados na apresentação de Costa (1978), quando diz: "Não seria 
legítimo interpretar um texto que se quer testemunha e não juiz da história”, como também o de salientar o esforço dos autores "de provar que não há por que pensar poder e saber imobilizados numa polaridade maniqueísta”.

\section{A questão da saúde no período de 1870-1930}

$\mathrm{Na}$ continuidade dos estudos que tentaram dar conta da reconstrução histórico-social da saúde, verificou-se que havia necessidade de aprofundar o conhecimento de um amplo período da história brasileira - de 1870 a 1930 . Luz (1982), que orientou diversos projetos de investigação histórica na saúde, acentuava o fato de que "a questão da saúde na formação brasileira adquire, no período de 1870-1930, contornos mais nítidos e definidos que em outras conjunturas, dada a particularidade do momento de bruscas mudanças no conjunto da sociedade". São apontados pela autora, que no plano interno, ocorre a crise do modelo imperial escravagista e no externo uma redefinição da hegemonia nacional do capitalismo. Para este período definem-se 4 subconjunturas: (1) 1870-1889, (2) 1889-1894, (3) 1894-1918 e (4) 1918-1930.

Tomando esta orientação cronológica como ponto de partida são enumerados alguns trabalhos que se dedicaram de diferentes maneiras e com objetivos diversos a pesquisar as questões da saúde nessas conjunturas em distintas realidades brasileiras: Mascarenhas (1949), Blount (1971), Oliveira (1983), Mehry (1985), Moraes (1983), Costa (1985), Bodstein (1984), Bertolli Filho (1986), Santos (1987), Ribeiro (1993), Telarolli Jr. (1993), Hochman (1998).

Sem a pretensão de ser exaustivo na revisão, verifica-se, pela relação, que o tema, paulatinamente, vem atraindo o interesse dos estudiosos. Também, não se pretende tratar detalhadamente de todas as obras citadas, mas situar seus principais aspectos. Torna-se necessário, entretanto, de forma geral, delinear alguns pontos que demarquem esse período que vem merecendo tanta atenção daqueles que se dedicam ao estudo da saúde pública.

\section{Características gerais do período}

Os historiadores são unânimes em analisar o período de vinte anos que antecedem a Proclamação da República como de transição e crise. Moraes (1983) sintetiza esse período no qual o escravismo irá ceder lugar a outras formas de produção pré-capitalistas (nas regiões Norte e Nordeste) e capitalistas (São Paulo e Rio de Janeiro). A expansão cafeeira irá colocar como problema fundamental a substituição da mão-de-obra escrava, que virá encontrar nos imigrantes europeus a constituição de uma nova força de trabalho. A ocorrência de um processo de modernização da capital do Império será acompanhada de um processo político de centralização do Estado Imperial, que irá entrar em crise após 1870 . Ocorrências como o fortalecimento do Exército, a crise entre a Igreja e o Estado, a crise e deterioração do Partido Liberal, com o crescimento da ideologia republicana, pressões externas e internas contra a escravidão, a política inflacionária dos anos 80 , revelam a transição do escravismo para o capitalismo e da Monarquia para a República.

João Cruz Costa (1967), em Contribuição à história das idéias no Brasil, escreveu: "O decênio que vai de 1868 a 1878 é o mais notável de quantos no século XIX constituíram a nossa vida espiritual. (...) Até 1868, o catolicismo reinante não tinha sofrido nestas plagas o mais leve abalo; a filosofia espiritualista, católica e eclética, a mais insignificante oposição; a autoridade das instituições monárquicas, o menor ataque sério por qualquer classe do povo; a instituição servil e os direitos tradicionais do feudalismo prático dos grandes proprietários, a mais indireta opugnação; o romantismo, com os seus doces, enganosos e encantadores cismares, a mais apagada desavença reatora. Tudo tinha adormecido à sombra do manto do príncipe feliz que havia acabado com o caudilhismo nas províncias e na América do Sul e preparado a engrenagem da peça política de centralização mais coesa que já uma vez houve na história de um grande país. De repente, por um movimento subterrâneo, que vinha de longe, a instabilidade de todas as coisas se mostrou e o sofisma do Império apareceu em toda a sua nudez".

Em realidade, duas questões que mereceriam uma análise mais detalhada, mas que fogem ao nosso objeto, a questão militar e a questão religiosa, serão cruciais nesse período. Cumpre destacar que "O momento de crise faz surgir propostas variadas. Os médicos, reunidos em associações corporativas, desenvolvem modelos de cura da sociedade. Advogados propõem novas relações jurídicas e de 
poder. Militares contestam o poder e o sistema hierárquico, etc." (Moraes, 1983). Em resumo: impunha-se uma estrutura de poder diferente da até então vigente - a República. Como escrevem Santos e colaboradores (1964), “a República resultou das lutas travadas pelos grandes contingentes urbanos das camadas médias apoiados por todos os setores populares da nação, da burguesia nascente e fração do latifúndio do café que abandonara o trabalho escravo". De fato, nesse momento, a participação do operariado, embora tenha estado presente, será pequena, dado a sua insipiência, e o Exército "representou a vanguarda da classe média e de todas as classes sociais que apoiava a mudança do regime”. As formas de resistência do operariado irão ocorrer mais intensamente no período que se estende de 1917 e 1919, através de inúmeras greves, movimento que recebeu detalhada análise por parte de Soares (1985). Nesse estudo a autora situa, para o período de 1890 a 1920 , as reivindicações de saúde feitas pelos trabalhadores.

Das diversas conjunturas que formam a República Velha, a primeira, conhecida como a "República da Espada", os historiadores marcam como sendo o período em que se estabelecem as alianças entre os militares e os cafeicultores paulistas. Os primeiros, marcadamente positivistas, pretendem dar a característica ideológica à República; os cafeicultores queriam o federalismo, o liberalismo econômico e político, uma nova Constituição; é uma época de crises, com sucessivas rebeliões militares e quedas de ministros. Se, de um lado, o Exército defende a centralização político-administrativa, de outro, os cafeicultores viam na descentralização a solução para os problemas. Em conseqüência, ocorre a ruptura da aliança.

Esse período, que vai de 1889 a 1894, será sucedido por outra conjuntura, na qual os cafeicultores aliam-se às oligarquias regionais dominantes, em São Paulo e Minas Gerais, com predomínio dos interesses da exploração do café sobre o conjunto da sociedade nacional. Esta conjuntura estende-se de 1894 a 1914, no momento em que o Brasil se vê atingido pelos efeitos da Primeira Guerra Mundial, com a diminuição das importações de café e borracha. A crise do modelo será a principal característica da conjuntura de 1914 a 1930, ou seja, a do modelo agro-exportador. Com ele instala-se não somente um forte controle social e institucional das camadas médias e do ope- rariado, como também há crescente aumento do custo de vida e baixa salarial. Constantes rebeliões irão ocorrer: 1912, 1914, 1915, 1930. Época marcada por profundas mudanças e rupturas, com crescente complexificação da vida urbana.

Mehry (1985) lembra que, embora possam existir diferentes interpretações sobre o primeiro período da República, "é de consenso, entretanto, que o processo de instauração da República no Brasil reflete especificações próprias do desenvolvimento capitalista especifico nessa sociedade, não reproduzindo os mesmos passos do desenvolvimento social dos países centrais. Portanto, as relações entre capital industrial e agrário, entre burguesia e revolução democrática, obedecem a padrões próprios de desenvolvimento".

\section{Revendo os estudos}

Dentro da linha de pesquisas inauguradas por Machado e colaboradores, coloca-se o trabalho de Oliveira (1983) que ao abranger o período de 1866-1896, busca esclarecer o papel dos intelectuais formuladores de discursos científicos e políticos, em especial aqueles dirigidos a promover a intervenção médica no corpo social. O pressuposto é que se podem estudar "os projetos médico-sociais, como uma das bases sobre a qual se apoiam tentativas de dominação de uma determinada fração ou classe sobre as demais" (Oliveira, 1983). Para tal, há necessidade de articular ideologia política e científica. A fim de tratar estes pressupostos, o autor analisa a maneira como se estruturou o modelo experimental que informa o sanitarismo no Brasil. Para isso, toma as propostas desenvolvidas por dois grupos que eram contemporâneos: a Sociedade de Medicina e Cirurgia do Rio de Janeiro e a "Escola Tropicalista Baiana”.

Como explica Oliveira, "No sentido de apresentar o modelo de conhecimento de ambas, tomamos, como exemplo, a ancilostomíase, doença muito freqüente no Brasil. Procuramos demonstrar como estes dois projetos de medicina social, partindo de pressupostos teóricos bastante diversos, ao trabalhar com os mesmos elementos - clima, habitação, costumes, condições sociais, condições geográficas - delineiam objetos e desenvolvem teorias também bastante diversas" (Oliveira, 1983). Outras doenças como o beribéri e o cólera são 
analisadas do ponto de vista da "Escola Tropicalista”. A análise é completada com o estudo da organização do ensino médico, através das duas primeiras instituições estatais criadas no pais: a de Salvador (Bahia) e a do Rio de Janeiro. É também feito um relato sucinto sobre a medicina legal e antropologia, que como afirma, "progressivamente vão suplantando em importância política os estudos de higiene propriamente ditos". De um modo geral, com este estudo pretende-se avançar na investigação sobre as origens institucionais da medicina social no Brasil.

Trata-se de minucioso estudo do qual algumas conclusões são importantes: (1) o caráter inovador da Escola Tropicalista, ao divulgar o modelo anglo-germânico que se baseava no método experimental, incluindo a divulgação do microscópio, da estatística e da anatomia patológica; (2) a não-dependência exclusiva dos projetos de medicina social da produção econômica, na medida que podem surgir "num momento em que a fração de classe que poderia apoiá-los não fosse dominante e, como tal, não tivesse condições de implementá-los" (Oliveira, 1983); (3) quanto à relação entre os interesses do Estado e os projetos de medicina social, percebe-se a presença da idéia do controle social, tanto no momento em que predomina a perspectiva da higiene através do controle sanitário da população, quanto no da medicina legal, através do controle jurídicoadminisitrativo.

O trabalho de Moraes (1983) irá também procurar desvendar, numa conjuntura específica - o período de 1914-1930 -, o discurso da Academia Nacional de Medicina e da imprensa, através do jornal O Estado de São Paulo, sobre a saúde, ou seja, a análise do discurso de uma instituição e sobre uma instituição. Machado (1978) já havia apontado que, desde 1829, quando surge a Sociedade de Medicina e Cirurgia do Rio de Janeiro e depois a Academia Imperial de Medicina (instituída através de decreto regencial, em 8/5/1835), essas instituições estabelecem como seus objetivos a defesa da ciência médica e a preocupação com a saúde pública. Importante destacar a defesa do saber médico e sua relação com o Estado, na medida que "ao mesmo tempo em que a medicina enquanto medicina social oferece ao Estado seus préstimos no combate às epidemias, na elaboração da legislação, distribuição da justiça, urbanização, cobra dele a luta contra o charlatanismo e o reconhecimento da exclusividade do saber sobre a saúde". A proscrição do charlatanismo é ponto de honra. Deve-se marcar, entretanto, que a sociedade estabelece um discurso médico sobre as cidades, pois estas são consideradas como as causas de doenças e de desordens (Oliveira, 1983). Em relação à Academia Nacional de Medicina (foi em 21 de novembro de 1891, que o Governo da República, modificou a denominação da Academia Imperial, para Academia Nacional de Medicina), Moraes (1983) aponta que ela "não consegue, nesse período [1914 a 1930], impor seu projeto médico em face da sociedade”.

Qual era esse projeto? Com a palavra, Moraes (1983): "O discurso da ANM que fala em atenção à população não é um projeto de medicina de massa; a ANM luta pela universalização da atenção médica que se transformava, em nosso período de análise, numa prática especializadora e necessariamente clínica. O modelo de intervenção da ANM é um modelo de intervenção individualizador e que implica vultosos custos".

Num estado com uma ideologia liberal, a medicina se identifica com ele, em sua prática e no seu modelo de medicina social. Como prossegue o autor, "O Estado, entretanto, vive outra realidade e representa outros setores e alianças sociais que não estão representadas na ANM. O Estado faz do sanitarismo seu projeto médico-social dominante, no período de nossa análise". Tanto assim, que em 1923 é criada, no Rio de Janeiro, a Sociedade Brasileira de Higiene e, em 1927, o Sindicato Médico do Rio de Janeiro.

Qual é o projeto do Estado, em relação à saúde? É o campanhismo. O modelo de médico e de cientista é Oswaldo Cruz. O saber assenta-se na pesquisa e na experimentação. Objetivo: combater as endemias e as epidemias. Mil novecentos e dezoito é um ano marcado pela gripe espanhola e 1928 pelo ressurgimento da febre amarela. Lembre-se que Oswaldo Cruz desenvolveu toda a sua ação, que se inicia em 1900, fora dos quadros da ANM, não tendo esta se envolvido nas campanhas sanitárias. O Instituto Oswaldo Cruz (esta denominação foi dada pelo Governo Federal em 1908), cujo nome anterior era Instituto Manguinhos, tem a sua origem no Instituto Soroterápico Federal, inaugurado oficialmente em 30 de julho de 1900. Interessante que em sua pesquisa, Moraes (1983) vai dialogar também com a "opinião pública" quando exposta por um órgão da imprensa, o jornal O Estado de São 
Paulo - "um jornal que tem como compromisso apaziguar as contradições e os conflitos sociais sem despertar a população para os perigos que a 'desordem' representa”.

Analisando conjuntamente o papel dos intelectuais da Academia Nacional de Medicina e de O Estado de São Paulo, Moraes (1983), conclui que "isolados social e politicamente, lutam por impor seus projetos, que têm em comum a tutela da sociedade e a possibilidade de, com seus saberes e práticas, ajudarem a gerir a sociedade e o Estado. Os projetos médico-sociais no ESP e na ANM não expressam apenas o autoritarismo e a exclusão de setores populares em sua discussão ou imposição; eles têm em comum a busca do poder que deveria acompanhar cada prática e saber".

Novamente, a referência à análise de Carvalho e Lima (1992) torna-se necessária, quando situam que o problema nesse trabalho é "o estabelecimento de correlações imediatas entre os modelos de conhecimento científico e interesses de grupos e classes sociais, que são igualmente pouco qualificados”. Acrescentam, também, que "uma constante nesses trabalhos parece ser a pouca historicidade conferida à noção de cidade no Brasil daquele contexto".

Contemporâneos do trabalho de Moraes (1983) são os de Costa e de Mehry, apresentados inicialmente como dissertações de mestrado e publicados posteriormente. Ambos voltam-se para a análise do saber/práticas sanitárias/instituições de saúde e suas relações, no espaço criado pelo impacto das transformações econômicas e políticas das três primeiras décadas deste século, ou seja, de como as políticas de saúde responderam às demandas históricas do capitalismo brasileiro. No caso de Costa (1985), para demonstrar como se deu a ascensão da vertente sanitarista, o autor estuda dois grandes momentos políticos: a "conjuntura Oswaldo Cruz", inaugurando a organização da saúde e moldes científicos com base na bacteriologia e microbiologia, assim como das ações voltadas para a imanização através de vacinas; e o período de 1918-1924, marcado pela criação do Departamento Nacional de Saúde Pública e pelas Reformas Sanitárias de Carlos Chagas. Coloca em evidência a ocorrência, nesse período, de um processo de institucionalização e rotinização de medidas sanitárias com a criação de diversos aparelhos estatais de saúde pública. Deve-se mencionar que a Constituição de 1891 irá determinar que os Estados são responsáveis pela saúde públi- ca em suas diversas áreas, o que levaria os Estados mais capacitados a criarem inúmeros órgãos sanitários. Lembre-se, também, que a política de Oswaldo Cruz deixa de lado a questão da tuberculose, primeira causa de morte durante todo o período de 1890 a 1934, e dedicase às doenças epidêmicas, como pode ser visto no estudo de Bodstein (1984).

Mehry (1985) privilegia em seu trabalho o Estado de São Paulo, que nesse momento já se tornava o pólo econômico e social mais importante do Brasil. A proposta é exatamente saber como o conjunto das práticas sanitárias contribuiu para a organização da sociedade, segundo os interesses dominantes da oligarquia agro-exportadora, cuja fração hegemônica era ligada ao setor cafeeiro em Minas Gerais e São Paulo (Mehry 1985). Considere-se que esta perspectiva de análise irá questionar, como esclarece o autor, as bases metodológicas de um dos primeiros estudos sobre a administração sanitária em São Paulo, escrito por Rodolfo Mascarenhas, em 1949. Nesse estudo, como nos de Blount (1971), as práticas no campo da saúde pública são analisadas a partir do tipo de conhecimento que se incorpora nas estruturas dos serviços e que acabam se concentrando no estudo da obra científica de "grandes" personagens históricos, considerados "portadores da ciência”, ou centrados na análise da organização institucional da saúde pública, ou seja, passa-se a tentar entender o campo das práticas através de instituições específicas.

Em resumo: identificar e solucionar os problemas sanitários é atribuição das ciências e de seus portadores, os técnicos. Quando os problemas persistem, a culpa é a inexistência de um conhecimento naquele momento, ou se deve "à irracionalidade da administração dos meios necessários para efetivá-los" (Mehry, 1985). De outro lado, "O avanço histórico de determinados conhecimentos científicos obedece a um sentido linear e evolutivo", em especial na medida que as pesquisas se realizam no quadro de referência do método científico, nos padrões das ciências naturais (Mehry, 1985). Ou seja, tendo como base "a fé na ciência experimental biomédica”, como escreve Luz (1982), ao se referir a Oswaldo Cruz e ao seu projeto científico, que era também um projeto político, traduzido no sanitarismo, como já foi referido em outro momento deste trabalho.

A base do conhecimento é a bacteriologia e a personalidade que se destaca é Emílio Ri- 
bas, cujo papel, de 1897 até 1917, é marcante frente à diretoria do Serviço Sanitário Estadual, e mostra "a consolidação da era pasteuriana da Saúde Pública paulista” (Mehry, 1985). As suas práticas visam atingir algumas doenças infectocontagiosas e "confere-lhes uma razoável capacidade para responder adequadamente aos surtos epidêmicos" (Mehry, 1985), mas, como é analisado, não há interferência nas condições determinantes da deterioração das condições de vida e de trabalho. $\mathrm{Na}$ medida que este modelo da atuação de caráter campanhista e mesmo o arcaísmo do Código Sanitário, aliado à estrutura dos serviços, não conseguem ser suficientes, a saúde pública começa a perder o monopólio dos serviços (Mehry, 1985). Blount (1971), em sua tese, escreve sobre "The Era of Emílio Ribas" e assinala que "de muitas maneiras, a campanha de Ribas (refere-se ao controle dos surtos de febre amarela) em São Paulo precede e fornece um exemplo para as campanhas sanitárias da cidade do Rio de Janeiro por Oswaldo Cruz. As inovações paulistas em sanitarismo e higiene, e os políticos que apoiaram estes programas de saúde, foram parcialmente responsáveis pelo uso posterior de técnicas similares na capital nacional". Isto comprovaria, segundo Santos (1980), a tese da descentralização do poder, no momento em que "mecanismos de centralização estavam operando em escala nacional". Para este autor, endossando as observações de Blount (1971), há, entretanto, uma outra explicação: São Paulo, desde a época do Império, já encaminhava medidas sanitárias, que teriam sido a base de "progressos subseqüentes".

A partir dos anos 20, mudanças ocorrem; entre elas, assiste-se à ascensão da assistência médica individual. No campo da saúde pública, a reformulação viria com o dr. Geraldo Horácio de Paula Souza, designado diretor do Serviço Sanitário Estadual, em 1922. Com ele inaugura-se, em 1925, a primeira reforma da fase chamada "médico-sanitária", onde o projeto de saúde estará claramente vinculado às ações da Educação Sanitária, realizadas através dos Centros de Saúde. Assim, a Saúde Pública deve ter um caráter social, promovendo e protegendo a saúde.

Quase todos os estudos sobre a saúde no período da República Velha citam a pesquisa de Blount, também já referida nesta apresentação. Trata-se de um trabalho escrito no início dos anos 70 e apresentado como tese de doutorado na Tulane University. Posteriormente, o autor escreveu um resumo deste trabalho, publicado na Revista de Administração de Empresas, em 1972. Seu estudo sobre o Serviço Sanitário do Estado de São Paulo cobre o período de 1892-1918, sendo bastante detalhado. O autor chama a atenção para o fato de que "o movimento sanitário de São Paulo é incomum na história da saúde mundial, por causa da maneira como se desenvolveu e a rapidez com que foi implementado. A campanha foi similar em alguns aspectos à política de saúde desenvolvida por Bismark na Alemanha". O período em estudo teve como fontes importantes de informação três jornais que se tornaram porta-vozes da causa republicana: $O$ Estado de São Paulo, o Correio Paulistano e o Diário Popular.

A importância deste estudo revela-se, entre outros aspectos, por ter chamado a atenção para o fato que, tanto os políticos paulistas, como os diretores de serviços, aceitaram e aplicaram rapidamente as descobertas da revolução bacteriológica, demonstrando inclusive, pelo estabelecimento de um vasto complexo institucional voltado para a pesquisa e produção de vacinas. De outro lado, enfatiza que o avanço da intervenção estatal em saneamento e higiene em São Paulo foi devido ao intenso programa defendido pelos interesses dos proprietários paulistas em trazer imigrantes para o Brasil. Segundo Blount (1971), era necessário que se tomassem medidas de saúde, pois a imigração aumentava a possibilidade de doenças, mas estas, também, impediam que os imigrantes se sentissem atraídos para locais que se mantivessem insalubres. Santos (1980) aponta que a hipótese que relaciona os interesses do café à imigração, em conseqüência ao movimento de saúde pública, necessita ser melhor especificada. Não pode, segundo a sua visão, ser apontada como o único fator explicativo do movimento sanitário paulista.

Antes de se comentar a questão da imigração é interessante assinalar algumas críticas feitas ao trabalho de Blount, que de certa forma, segue o sempre destacado estudo de Mascarenhas (1949). Para Telarolli Junior (1993), o trabalho de Mascarenhas segue a tradição que decorre de uma concepção de história dominante no Brasil nos anos 40, ou seja, "de uma sucessão linear de acontecimentos produzidos exclusivamente pela ação dos dirigentes políticos, administradores, médicos etc., que foram se sucedendo". O que importa na de- 
terminação dos acontecimentos é a qualificação individual dos dirigentes dos serviços sanitários. Mesmo considerando que o estudo de Blount aponta para algumas relações entre o modelo político e a organização dos serviços sanitários, permanece a visão de que "reduz a complexidade dos fatos às aliterações no arcabouço legal”.

Quanto ao tema da imigração, este volta a ser detalhadamente explorado num dos mais recentes textos que trata da saúde pública em São Paulo. Refiro-me à tese de Maria Alice Rosa Ribeiro, apresentada em 1991, e publicada em 1993. Conforme a autora, "A experiência pioneira de constituição do mercado de trabalho é o ponto de partida deste estudo sobre a saúde pública no Estado de São Paulo. A escolha desse ponto não é aleatória, já que entendo que o Estado ao assumir a responsabilidade de criar o mercado de trabalho livre não pode se restringir à organização da corrente imigratória, tem que estender sua ação em direção à montagem de uma infra-estrutura institucional para atender aos problemas colocados pelo rápido crescimento da população". O trabalho não se limita a estabelecer esta relação de maneira mecânica, mas contextualiza as amplas transformações ocorridas com a cultura cafeeira, suas repercussões na situação demográfica e como ela definiu a política imigratória, que como escreve a autora, "desenhou uma distribuição da população e fixou uma densidade populacional entre as regiões do Estado, e, por fim, trouxe problemas de saúde pública" (Ribeiro, 1993).

Estende-se o estudo na compreensão do processo de urbanização, como um processo originário da própria expansão cafeeira e posteriormente estimulado pela industrialização e que ocasionaria profundas transformações, em especial na capital do Estado. O estudo cobre, em quatro capítulos, quatro conjunturas: a segunda metade da década de 1880 até 1890; de 1890 até 1914, com ênfase nos acontecimentos na capital de São Paulo, lembrando que, em 1911, a reforma do Código Sanitário de 1894 "se encarregará de forma mais enfática dos problemas de urbanização desordenada da Capital" (Ribeiro, 1993); de 1914 a 1920 "acompanha o retorno da população ao campo e às cidades, no interior do Estado", sendo que nesse período, em 1917, é elaborado o Código Sanitário Rural; os anos 20, "os anos da ruptura” - "ruptura com o academicismo, ruptura com o século XIX, ruptura do capital industrial com o capital comercial, ruptura na política de saúde" (Ribeiro). Encerra o trabalho com a Reforma Paula Souza que, como já foi citado anteriormente, estabelece um novo modelo de atuação - a ação educativa que, como conclui a autora, vai expor "de forma mais clara, a ideologia e o autoritarismo da prática sanitária”. Escamoteando as diferenças de classe, reduzindo-as a diferenças educacionais "o doente é responsável pela doença por ser ignorante" -, lança no campo da saúde pública a nova personagem, a educadora sanitária.

Dentre outras sugestões, Santos (1980) havia sugerido que um ponto a ser melhor estudado relacionava-se à influência das idéias positivistas na aplicação e na difusão do conhecimento científico. Este será um assunto que Ribeiro (1993) irá abordar. Nesse trabalho fica demonstrado que, em São Paulo, a influência do comtismo foi diferente da que se desenvolveu no Rio de Janeiro. O dr. Luiz Pereira Barreto, que viria a ser o primeiro presidente da Sociedade de Medicina e Cirurgia de São Paulo (1905), formado na Europa e tendo sofrido as influências do positivismo, chegou a divulgar as idéias de Comte no Brasil. Mas veio a divergir do positivismo ortodoxo, pregado no Rio de Janeiro não tendo aderido à campanha contra a vacinação obrigatória, movida pelo Apostolado Positivista; segundo ele, era dever do cidadão submeter-se à vacina obrigatória contra a varíola. Lopes (1988) também reporta sobre as divergências entre os positivistas, citando a posição do dr. Pereira Barreto.

Tanto a questão da vacinação como a do positivismo já foram estudadas pela literatura. Sevcenko (1984) analisa a Revolta da Vacina; Lopes (1988) retoma o tema, assim como Meihy e Bertolli Filho (1990). No caso de Lopes (1988), a autora faz uma leitura da Revolta da Vacina, no Rio de Janeiro, a partir dos alvos de ataque dos cariocas. No seu dizer, "A apropriação das ruas, a quebra de bondes e a construção de barricadas formam uma experiência singular de alguns habitantes no espaço urbano. Há uma recodificação da grafia urbana onde os símbolos da civilização são reapropriados e se transformam em táticas de luta da população. Resistência física que atinge alvos precisos e expressa uma trajetória do desejo da população amotinada”. A revolta durou do dia 10 a 23 de novembro de 1904. As forças repressivas mapearam a cidade e o estado de sítio foi decretado no Rio de Janeiro e Niterói. Quando a revolta foi pulverizada, "A repressão 
aproveitou para fazer uma "limpeza" preventiva nas áreas consideradas suspeitas pelas autoridades. Os presos, em torno de setecentos, aguardaram na Ilha das Cobras antes de serem enviados para o Acre" (Lopes, 1988).

Também o tema do positivismo é trazido pela autora, quando analisa o debate entre os clínicos positivistas e os adeptos da bacteriologia e da anatomia patológica. Como escreve, "luta política sobre a forma de gestão dos corpos e do meio". Todo o trabalho é no sentido de reconstruir as práticas sanitárias e o espaço urbano. Nesse sentido, são analisadas as críticas positivistas à vacinação, à assistência médico-hospitalar e ao papel biológico-político da mulher. Segundo a autora: "A campanha contra o Código Sanitário, levada pelos positivistas, encontra eco junto à população que se sente violentada e privada de seus direitos, através de medidas como expurgos, seqüestro e internamento de doentes em hospitais de isolamento, desapropriação e demolição de moradias tidas como insalubres, perseguição às tinas das lavadeiras, proibição de romarias e visita aos cemitérios em época de epidemias, dentre outras".

Antes de um rápido resumo sobre a produção que se estende dos anos 30 até a atualidade, deve-se destacar que, na produção sobre a saúde pública na República Velha, há algumas pesquisas que embora tratem de "estudos de casos", fazem-no de maneira bastante especial. Refiro-me aos estudos de Bertolli Filho (1986) sobre a gripe espanhola em São Paulo, de Telarolli Junior (1993) sobre a febre amarela na cidade de Araraquara (SP) e de Meihy e Bertolli Filho (1990) que trata da campanha da vacina em 1904 no Rio de Janeiro, de Matos (1992) sobre a malária em São Paulo.

Sem pretender resumir estes trabalhos, deve-se considerá-los dentro de uma linha que, ao privilegiar aspectos específicos, não se limitam a uma historiografia sobre os eventos. Meihy e Bertolli Filho têm palavras bastante esclarecedoras quando destacam a importância dos "estudos de casos". Para eles: “Os 'estudos de casos' quase sempre ressaltam a inevitabilidade do conflito social. Aceitando o isolamento de algumas situações, fica então implícita a circunstancialidade do fenômeno e suas superações. Esquecendo-se que na maioria das vezes os estudos da saúde devem tratar de situações recorrentes e que deitam raízes em longínquos tempos, os recortes temáticos só ganham sentido explicativo se, depois de isolados do passado forem mesclados com outras crises que também são considerações episódicas".

Assim, o próprio estudo de Meihy e Bertolli Filho (1990) procura entender a Revolta da Vacina num contexto no qual se inter-relacionam as ações do Estado, da medicina e saúde e do controle popular. Quanto ao trabalho de Telarolli Junior (1993), nas palavras do próprio autor "A investigação atravessa diversos momentos, estando imersa na análise histórica dos correspondentes quadros demógrafosanitário, econômico e político privilegiandose o ponto de vista das relações entre o Estado federado e os municípios". Especifica, ainda, ao privilegiar o estudo da febre amarela, quando afirma: "As epidemias de febre amarela no período (1889-1911) são o aspecto destacado do ponto de vista sanitário para a identificação e estudo do conjunto de conhecimentos subjacentes ao modelo tecno-assistencial campanhista/policial, bem como ao modelo gerencial dos serviços de saúde no Estado de São Paulo". Também no estudo da gripe espanhola de 1918, como escreve Bertolli Filho (1986), busca-se compreender "a determinação social da gripe espanhola", as "respostas coletivas e as pessoais, a reação do governo e das instituições públicas", no sentido de entender o impacto da doença sobre a cidade.

Fundamental para a compreensão da saúde pública brasileira na Primeira República é o trabalho de Hochman (1998). Nele, o autor, como escreve Renato Lessa, na Apresentação, "pretende demonstrar a centralidade assumida pelas políticas de saúde e saneamento, no Brasil da Primeira República, no processo de construção do Estado Nacional. Em termos mais diretos, aquelas políticas são apresentadas como cruciais para o alargamento da presença do Estado na sociedade e no território brasileiros" (Hochman, 1998). Através de detalhada pesquisa histórica associada a um denso quadro de referência sociológica, às quais se junta a análise crítica de muitos autores que estudaram a saúde pública nesse período, o autor alcança plenamente os objetivos por ele colocados, ou seja, que "uma política nacional de saúde pública no Brasil foi possível e viável a partir do encontro da consciência das elites com seus interesses, e suas bases foram estabelecidas a partir de uma negociação entre os estados e o poder central, tendo o federalismo como moldura político-institucional" (Hochman, 1998). Para o autor, "Este encon- 
tro foi promovido pelo movimento sanitarista brasileiro que buscou redefinir, entre 1910 e 1920, as fronteiras entre os sertões e o litoral, entre o interior e as cidades, entre o Brasil rural e o urbano em função do que consideravam o principal problema nacional: a saúde pública”.

Sem a pretensão de sumarizar o extenso trabalho feito por Gilberto Hochman, destaco um aspecto inicial que me parece extremamente importante. Este aspecto refere-se ao ponto de partida deste trabalho que está calcado na compreensão do movimento da reforma da saúde pública, nas primeiras décadas do século XX, "como um dos elementos mais importantes no processo de construção de uma ideologia da nacionalidade, com impactos relevantes na formação do Estado brasileiro". Como diz o autor, embora muitos estudiosos, como Costa (1985), Mehry (1985), Ribeiro (1993) partilhem desta interpretação mais geral, seus trabalhos enfatizam aspectos específicos das políticas de saúde: interesses das classes dominantes, associados "à dinâmica do capitalismo, tanto do ponto de vista doméstico como internacional" e "consideram os principais atores públicos, especialmente os sanitaristas e dirigentes da saúde pública, como intelectuais subordinados aos interesses dos grupos dominantes, nacionais e estrangeiros" (Hochman, 1998). Vários são os modelos e conceitos que orientaram o autor: o crescimento da interdependência social e da tomada de consciência a seu respeito de De Swaan; o conceito de poder despótico e poder infra-estrutural, de Mann; o neoinstitucionalismo histórico, de Skocpol e Immergut.

De outro lado, são básicas para este trabalho as idéias desenvolvidas por Elisa Reis em relação às políticas econômicas, como também, as de Luís Antônio de Castro Santos, sobre o movimento sanitarista na Primeira República. Da identificação da doença, como um elo de interdependência social, à sua transformação em problema político, o autor salienta que "as propostas de minimização dos efeitos negativos da interdependência indicam que a centralização administrativa e a autonomia técnica eram consideradas soluções lógicas para o problema" (Hochman, 1998). Assim, o autor expõe de forma detalhada a organização sanitária do início da República até meados da década de 1910, data em que se institui a Liga Pró-Saneamento do Brasil, e as propostas de reforma sanitária entre 1918 e 1920, em especial a criação do Departamento Nacional de Saúde Pública (DNSP), em 1919. Como escreve Hochman (1998), ao traçar as considerações finais sobre esse momento da sua análise, "a reforma foi o resultado de um acordo político que envolveu um grande número de pactuantes, os quais abriram mão, gradativamente, de suas posições dogmáticas iniciais, fossem baseadas na Constituição, no conhecimento médico ou na penúria financeira”.

A seguir, o autor analisa "o poder central como solução dos problemas sanitários" e como os estados aderiram prontamente à política do DNSP, avaliando que "os custos da alocação de atividades de saúde pública no Governo central - perda de autonomia - poderiam ser toleráveis, diante dos benefícios advindos dela - saneamento e profilaxia rural e dos custos da doença transmissível" (Hochman, 1998). Sem dúvida, é neste capítulo que o autor exemplifica toda a construção analítica que sustenta a sua argumentação: da interdependência sanitária e os benefícios e os custos, como diz, "percebidos e experimentados" pelos estados brasileiros na estatização da saúde, cujo contraponto é dado pelo Estado de São Paulo. Para Hochman (1998), as análises que destacam São Paulo "como o caso mais bem-sucedido na implantação de serviços sanitários estaduais, discutiram a especificidade paulista, sem relacioná-la com os dilemas nacionais que a tornaram possível” (....) "Minha hipótese é que São Paulo foi singular não porque se tenha alijado voluntariamente da questão sanitária nacional, mas justamente por se ter constituído como uma resposta aos problemas de interdependência sanitária enfrentados pelas elites brasileiras".

\section{Considerações finais}

Tendo tomado como orientação geral traçar um quadro da produção que vem se elaborando sobre a história da saúde pública, o destaque foi em relação aos trabalhos que tratam do tema até os anos 30. Ficam para uma próxima revisão aqueles estudos que analisaram a história nos anos que se seguiram à década de 1930, período que apresenta características bastante específicas. Nesse sentido, deve-se adiantar que a partir de 1930 "emerge e toma forma uma política nacional de saúde, mais precisamente, instalam-se os aparelhos necessários a sua efetivação" (Braga e Paula, 1981). 
Apresenta essa política, como analisam os autores, um caráter "restrito" em sua amplitude de cobertura populacional, assim como em seus aspectos técnicos e financeiros. O trabalho de Braga e Paula (1981), embora com ênfase nos aspectos econômicos, fornece um quadro analítico importante do período que se estende de 1930 até o início da segunda metade dos anos 70, com destaque à medicina previdenciária.

Outra pesquisa que irá incluir período posterior a 30 é de autoria de Iyda (1988). Analisa a saúde pública como parte integrante na constituição de um Estado burguês, englobando o período de 1889 a 1978, e se dedica, em especial, ao Estado de São Paulo.

Em seu mais recente trabalho, Mehry (1992) se detém em analisar o período de 1920 a 1948, onde procura fazer uma "leitura" das políticas governamentais como modelos tecno-assistenciais que se constituem em projetos das forças sociais; procuram-se, também, os vínculos que esses modelos estabelecem não só com as chamadas correntes tecnológicas de pensamento do campo das ações sanitárias, mas também com as questões políticas mais amplas, colocadas em seu campo especifico - arena decisória particular -, o qual define o significado social das referidas ações (Mehry, 1992).

Retomando o objeto desta apresentação, são feitas algumas considerações finais que parecem pertinentes à bibliografia levantada.

Em primeiro lugar, a importância crescente que vem sendo dada aos estudos históricos, com uma produção que alia o rigor da pesquisa histórica a uma perspectiva analítica que se volta para a compreensão mais completa dos contextos sociopolíticos de onde emergem as práticas sanitárias. Não se pode deixar de com- partilhar a posição de Carvalho e Lima (1992), quando comentam que as ciências sociais, ao reorientarem os estudos sobre a República Velha, já trouxeram e poderão ainda trazer importantes contribuições para as pesquisas na área da saúde. De outro lado, as próprias pesquisas aqui apresentadas mostram encaminhamentos diversos ao tema. Dentre eles aqueles que situam o desenvolvimento das práticas sanitárias da Primeira República como uma forma de assegurar a reprodução da força de trabalho, que, no dizer de Carvalho e Lima (1992), não revelam toda a diferenciação que existe quando se analisam determinadas conjunturas desse período. E como reforço dessa idéia, citam o trabalho de Santos (1987) que valoriza o "exame do sanitarismo enquanto ideologia de construção da nacionalidade". O trabalho de Hochman (1998), como foi visto neste ensaio de revisão coloca-se, também, dentro de outra vertente nos estudos sobre a saúde pública na Primeira República.

Por último e recorrendo a um ponto abordado por Meihy e Bertolli Filho (1990), ou seja, que se deve tomar com a devida precaução tanto as "histórias gerais", como os "estudos de casos”, quando se voltam para a história da saúde pública. Pois os primeiros podem ser vagos e generalizadores e os outros podem reduzir, em suas especificidades, problemas amplos e complexos. Como escrevem: "Acredita-se que sem a perspectiva diacrônica da relação de poder e das respostas sociais colocadas na perspectiva da "longa duração", seria impossível entender o significado de alguns fenômenos que vistos estruturalmente expõem o divórcio entre o discurso especializado, a vontade do governo e a aceitação geral das normas do tratamento médico".

\section{Referências bibliográficas}

Bertolli Filho C 1986. Epidemia e sociedade: a gripe espanhola no município de São Paulo. Dissertação de mestrado. Faculdade de Filosofia, Letras e Ciências Humanas, Universidade de São Paulo, São Paulo.

Blount JA 1971. The public health movement in São Paulo. Brazil. A history of the sanitary service: 1892-1918. Tese de doutorado. Tulane University.

Blount JA 1972. A administração da saúde pública no Estado de São Paulo: o serviço sanitário, 1892-1918. Revista de Administração de Empresas, Rio de Janeiro, $12(4): 40-48$. 
Bodstein RCA 1984. Condições de saúde e prática sanitária no Rio de Janeiro: 1890-1930. Dissertação de mestrado. Instituto de Ciências Humanas e Filosofia, Universidade Federal Fluminense, Niterói.

Braga JCS \& Paula SG 1981. Saúde e previdência: estu dos de política social. CEBES-Hucitec, São Paulo.

Carvalho MAR \& Lima NT 1992. O argumento histórico nas análises de saúde coletiva, pp. 117-242. In Fleury (org.). Saúde Coletiva: questionando a onipotência do social. Relume Dumará, Rio de Janeiro.

Costa JC 1967. Contribuição à história das idéias no Bra sil. Editora Civilização Brasileira, Rio de Janeiro.

Costa JF 1978. Apresentação. In Machado R et al. Danação da norma: medicina social e constituição da psiquiatria no Brasil. Graal, Rio de Janeiro.

Costa NR 1985. Lutas urbanas e controle sanitário: origens das políticas de saúde no Brasil. Vozes-Abrasco, Petrópolis-Rio de Janeiro.

Foucault M 1978. A arqueologia do saber. Vozes, Petrópolis.

Foucault M 1979. O nascimento da medicina social. In Machado R (org.). Microfísica do poder. Graal, Rio de Janeiro.

Hochman G 1998. A era do saneamento. Hucitec-ANPOCS, São Paulo.

Iyda M 1988. Saúde pública: reprodução ou legitimação. Tese de doutorado. Faculdade de Saúde Pública, Universidade de São Paulo.

Lopes MB 1988. Práticas médico-sanitárias e remodelação urbana na Cidade do Rio de Janeiro: 1890-1930. Dissertação de mestrado. Instituto de Filosofia e Ciências Humanas, Universidade Estadual de Campinas.

Luz MT 1982. Medicina e ordem política brasileira: politicas e instituições de saúde (1850-1930). Graal, Rio de Janeiro.

Machado R; Loureiro A; Luz R \& Muricy K 1978. Danação da norma: medicina social e constituição da psiquiatria no Brasil. Graal, Rio de Janeiro.

Mascarenhas RS 1949. Contribuição para o estudo da administração sanitária do Estado de São Paulo. Tese de livre-docência. Faculdade de Higiene e Saúde Pública, Universidade de São Paulo, São Paulo.
Matos ML 1992. A malária em São Paulo: epidemiologia e história. Dissertação de mestrado. Escola Paulista de Medicina.

Mehry EE 1985. O capitalismo e a saúde pública: a emergência das práticas sanitárias no Estado de São Paulo. Papirus, Campinas.

Mehry EE 1992. A saúde pública como política: um estudo de formuladores de políticas. Hucitec, São Paulo.

Meihy JCS \& Bertolli Filho C 1990. História social da saúde. Opinião pública versus poder. A Campanha da Vacina - 1904. São Paulo, Estudos CEDHAL, 5.

Moraes NA 1983. Saúde e poder na República Velha: 1914-1930. Dissertação de mestrado. Instituto de Filosofia e Ciências Sociais, Universidade Federal do Rio de Janeiro.

Oliveira CR 1983. Medicina e Estado - origem e desenvolvimento da medicina social - Bahia: 1866-1896. Dissertação de mestrado. Instituto de Medicina Social, Universidade do Estado do Rio de Janeiro.

Ribeiro MAR 1993. História sem fim. Inventário da saúde pública. São Paulo: 1880-1930. Editora da Universidade Estadual Paulista, São Paulo.

Santos LAC 1980. Estado e saúde pública no Brasil (1889-1930). Dados - Revista de Ciências Sociais, 23 (2):237-250

Santos LAC 1987. Power, ideology and public health in Brazil:1889-1930. Tese de doutorado. Tulane University.

Santos JR et al. 1964. História nova do Brasil - abolição. Advento da República e florianismo (vol. 4). Brasiliense, São Paulo.

Sevcenko N 1984. A revolta da vacina. Mentes insanas em corpos rebeldes. Brasiliense, São Paulo.

Soares, WDA 1985. Os trabalhadores e a questão da saúde: 1890-1920. Dissertação de mestrado. Escola Nacional de Saúde Pública, Fiocruz, Rio de Janeiro.

Telarolli Junior R 1993. Poder e saúde: a República, a febre amarela e a formação dos serviços sanitários no Estado de São Paulo (2 vol.). Tese de doutorado. Faculdade de Ciências Médicas, Universidade Estadual de Campinas. 